\title{
Recovery of bronchial epithelium on stopping smoking
}

\author{
JOHN F BERTRAM, ANDREW W ROGERS
}

\begin{abstract}
Bronchial biopsy specimens were studied from 19 patients, comprising five non-smokers, eight current smokers, and six people who had given up smoking between two and 16 years previously. By using a recently developed morphometric technique the structural state of the bronchial epithelium was assessed and described by a score, which specifies the extent to which the epithelial histology departs from the normal, through the changes of mucous-cell hyperplasia and squamouscell metaplasia. The epithelium was nearer normal in former smokers than current smokers in each of six pairs matched for smoking history.

The numerical scale permitted statistical analysis with a precision that is not possible with data based on subjective diagnosis alone: the results of comparing histology with pack-years of cigarette consumption were consistent with the hypothesis that structural recovery occurs in bronchial epithelium in people who stop smoking for over two years.
\end{abstract}

\section{Introduction}

The pseudostratified, ciliated epithelium of the bronchi changes on repeated exposure to irritants such as tobacco smoke. The early changes, or mucous-cell hyperplasia, include an increase in the relative number and size of mucus-secreting goblet cells. These changes may be followed by squamous-cell (or epidermoid) metaplasia, in which ciliated and goblet cells are replaced by a stratified squamous epithelium. Diagnostic grading of sections of bronchial epithelium, whether from biopsy or postmortem material, can readily be done by direct microscopy, but, in the absence of agreement among histopathologists on detailed

Unit of Human Morphology, Medical School, Flinders University, South Australia 5042

JOHN F BERTRAM, BSC, graduate student (present appointment: research officer, university department of pathology, Queen Elizabeth II Medical Centre, Nedlands, Western Australia 6009)

ANDREW W ROGERS, DSC, MB, professor of human morphology criteria for grading, ranking specimens in order of increasing abnormality is difficult and uncertain. This lack of precision matters little in routine diagnosis but makes it difficult to test hypotheses in experimental pathology, particularly with postmortem material, in which fine differences in structure may be lost.

For this reason it is hard to answer the question whether the changes in bronchial epithelium that occur with smoking are reversible. Auerbach et al ${ }^{1}$ examined postmortem material from over 200 patients, looking for the presence or absence of recognisable abnormalities of any sort. On correlating their observations with the smoking histories available they concluded that $26 \%$ of the sections from non-smokers showed abnormalities histologically compared with $98 \%$ of those from patients who had smoked up to the terminal illness. Results in patients who had given up smoking some time before death were intermediate, with $67 \%$ of sections showing abnormalities. In other work sputum samples were the basis for studies of the regression of metaplastic lesions when patients stopped smoking. ${ }^{2} 3$ The findings suggested some improvement, though squamous cells were still present five and seven years after patients had stopped smoking. In hamsters squamous-cell metaplasia induced by formaldehyde returned to normal in two to six weeks, while similar changes caused by exposure to benzo(a)pyrene progressed to persistent metaplasia with atypical features. ${ }^{4}$ In dogs squamous-cell metaplasia produced by direct application of cigarette condensate to bronchial epithelium for eight days recovered completely in 18 weeks. ${ }^{5}$ Isoprenaline-induced hyperplasia of secretory cells in pig airways is also reversible. ${ }^{6}$ Present evidence is thus far from conclusive. We carried out a study, using a new technique of measurement, in an effort to obtain more conclusive results.

\section{Methods \\ We recently developed a morphometric technique for assessing the structural state of bronchial epithelium. ${ }^{7}$ Briefly, material obtained at biopsy is fixed immediately, embedded in resin, and sectioned at $0.5 \mu \mathrm{m}$ for light microscopy: this provides histological material of high quality. Seven separate morphometric variables were found for each specimen: these were the epithelial thickness; the fractional area of sectioned epithelium occupied by nuclear profiles; the fractional area of sectioned epithelium occupied by histologically recognisable mucus; the mean distance between nuclei; the mean area of nuclear profiles;}


and the number of nuclei per unit area of sectioned epithelium and per unit length of basement membrane.

Cluster analysis of these data separated the patients into three welldefined groups. The same groupings resulted when the slides were examined visually by histopathologists and labelled as normal epithelium, mucous-cell hyperplasia, or squamous-cell metaplasia. The numerical data were transformed into a linear scale from -1.0 to $+1 \cdot 0$. On this scale specimens of bronchial epithelium that are histologically normal are grouped around $-0 \cdot 6$ : increasing degrees of mucous-cell hyperplasia produce values ranging from this figure up to around $0 \cdot 0$, while squamous-cell metaplasia scores around $+0 \cdot 4$. We then showed that similar groupings and scores could be obtained with the same patients when only three of the seven variables were used. These three measurements-namely, the epithelial thickness, the fraction of the epithelial area on sections occupied by histologically recognisable mucus, and the number of nuclear profiles per unit area of sectioned epithelium-contained all the information needed to describe the structural organisation of the epithelium in terms that agreed with visual diagnosis but possessed an additional objective reproducibility.

Present study-Biopsy specimens were obtained from patients undergoing diagnostic bronchoscopy; since respiratory epithelium may vary with the size of airway all specimens were taken from two specified sites-namely, where the right upper-lobe bronchus leaves the main-stem bronchus, and at the bifurcation of the left main bronchus. Detailed smoking histories were taken immediately before bronchoscopy. The specimens were fixed immediately in $3 \%$ glutaraldehyde and the usual histological steps followed, leading to embedment in resin (TAAB Laboratories, Reading); sections were cut at $0.5 \mu \mathrm{m}$ in a plane perpendicular to the epithelial surface. All material included in the study was free from pathological disease apart from the changes of mucous-cell hyperplasia and squamous-cell metaplasia. For each patient measurements were made on two sections from each of two blocks and the data transformed into the linear index of deviance from normality as described above. ${ }^{7}$ Initial experiments showed that the reduction in variance achieved by doubling the number of sections was not significant.

\section{Results}

In the first study we examined sections obtained from six pairs of patients, who had been matched as closely as possible for age, sex, smoking history, and other factors such as exposure to dusts and chemical irritants; one of each pair was a current smoker and the other a former smoker. The table shows that in each pair of patients the epithelial structure was nearer normal in the former smoker than the current smoker; this result was significant $(\mathrm{p}<0.05)$ (paired $t$ test, one tailed). $(p<0 \cdot 05)$. Former smokers $(n-6)$, despite the high numbers of packyears achieved by some of them, were statistically indistinguishable from non-smokers: the slope of the line of best fit was not significantly different from zero.

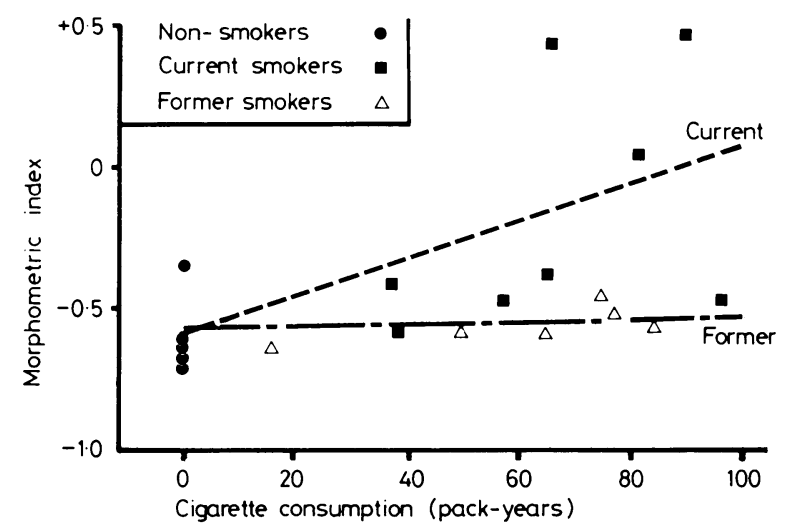

Change in morphometric index with total cigarette consumption. (Mean score for normal bronchial epithelium is -0.628 .)

\section{Discussion}

By obtaining histological material of high quality at biopsy and making carefully selected measurements we were able to test a hypothesis and achieve significant results with only a few patients. Our results are consistent with the hypothesis that many changes seen in bronchial epithelium as a consequence of smoking are reversible, and that normal histology is to be expected after non-smoking intervals of more than two years. Interestingly, the epidemiological evidence summarised in a report of the Surgeon-General of the USA ${ }^{8}$ indicates that mortality from lung cancer among former smokers approaches that among non-smokers after a non-smoking interval of 10-15 years.

Heavy smokers often ask whether it is worth giving up smoking and whether irreversible damage has already been done to their airways. Our results suggest that, apart from other benefits that may follow giving up smoking, appreciable recovery is to be expected in the epithelium of the respiratory tract.

Details of six pairs of matched patients (all men) with their scores on linear scale for epithelial histology

\begin{tabular}{|c|c|c|c|c|c|c|c|c|}
\hline Pair & Smoker & Age (years) & $\begin{array}{l}\text { Years of } \\
\text { smoking }\end{array}$ & $\begin{array}{l}\text { No of } \\
\text { cigarettes } \\
\text { a day }\end{array}$ & $\begin{array}{c}\text { No of } \\
\text { pack-years }\end{array}$ & $\begin{array}{c}\text { Duration of } \\
\text { non-smoking } \\
\text { interval } \\
\text { (years }\end{array}$ & $\begin{array}{l}\text { Qualitative } \\
\text { histology }\end{array}$ & Score \\
\hline & Current & 48 & 33 & 40 & 66 & 0 & SCM & +0.436 \\
\hline & Former & 54 & 38 & 40 & 76 & 4 & $\mathrm{MCH}$ & -0.467 \\
\hline & Current & 60 & 45 & 40 & 90 & 0 & $S C M$ & +0.464 \\
\hline & Former & 61 & 45 & 35 & 79 & 2 & $\mathrm{MCH}$ & -0.540 \\
\hline & Current & 64 & 52 & 25 & 65 & 0 & $\mathrm{MCH}$ & -0.378 \\
\hline & Former & 61 & 43 & 30 & 65 & 6 & Normal & -0.623 \\
\hline & Current & 52 & 38 & 20 & 38 & 0 & Normal/MCH & -0.607 \\
\hline & Former & 42 & 21 & 15 & 16 & 5 & Normal & -0.628 \\
\hline & Current & 59 & 47 & 25 & 59 & 0 & $\mathrm{MCH}$ & -0.477 \\
\hline & Former & 63 & 40 & 25 & 50 & 10 & Normal $\mathrm{MCH}$ & -0.586 \\
\hline & Current & 62 & 48 & 40 & 96 & 0 & $\mathrm{MCH}$ & -0.481 \\
\hline & Former & 57 & 28 & 60 & 84 & 16 & Normal/MCH & -0.571 \\
\hline
\end{tabular}

$\mathrm{SCM}=$ Squamous-cell metaplasia. $\mathrm{MCH}=$ Mucous-cell hyperplasia.

In the second study we extended these data by using in addition data available on smokers and non-smokers in our previous study. The numerical index of histological structure was plotted graphically against the number of pack-years of cigarettes consumed (figure). Non-smokers $(\mathbf{n}=5)$ formed a relatively homogeneous group: four had histologically normal epithelium, with values between -0.633 and -0.627 , while one showed mild mucous-cell hyperplasia. Current smokers $(n=8)$ showed much greater variability, but an increase in numerical index was obvious with increasing pack-years: the slope of the line of best fit for these results was significantly different from zero
We thank Dr Howard Brown, who carried out the bronchoscopies.

\section{References}

${ }^{1}$ Auerbach O, Stout AP, Hammond EC, Garfinkel L. Bronchial epithelium in former smokers. $N$ Engl 7 Med $1962 ; 267: 119-25$.

2 Saccomanno G, Saunders RP, Klein MG, Archer VE, Brennan L. Cytology of the lung in reference to irritant, individual sensitivity and healing. Acta Cytol 1970;14:377-81. 
${ }^{3}$ Plamenac P, Nikulin A, Pikula B. Cytology of the respiratory tract in former smokers. Acta Cytol 1972;16:256-60.

- Schreiber H, Bibbo M, Wied GL, Saccomanno G, Nettesheim P. Bronchial metaplasia as a benign or premalignant lesion. 1. Cytologic and ultrastructural discrimination between acute carcinogen effects and toxin-induced changes. Acta Cytol $1979 ; 23: 496-503$.

; Tipton DL, Crocker TT. Duration of bronchial squamous metaplasia produced in dogs by cigarette smoke condensate. Fournal of the National Cancer Institute 1964;33:487-95.

${ }^{6}$ Baskerville A. The development and persistence of bronchial gland hyper- trophy and goblet cell hyperplasia in the pig after injection of isoprenaline. $\mathcal{f}$ Pathol 1976;119:35-47.

7 Bertram JF, Rogers AW. The development of squamous cell metaplasia in human bronchial epithelium by light microscopic morphometry. $\mathfrak{f}$ Microsc $1981 ; \mathbf{1 2 3}: 61-73$.

${ }^{8}$ US Department of Health, Education and Welfare. Smoking and health: a report of the surgeon general. Washington: US Department of Health, Education and Welfare, 1979.

(Accepted 15 September 1981)

\title{
Role of mucosal injury in initiating recurrent aphthous stomatitis
}

\author{
DAVID WRAY, EDWARD A GRAYKOWSKI, ABNER LOUIS NOTKINS
}

\begin{abstract}
The buccal mucosa of 30 patients with recurrent aphthous stomatitis and $\mathbf{1 5}$ healthy controls was injured by suture and penetration with a tenaculum and a hypodermic needle and each of the six puncture wounds produced monitored for up to seven days for the development of ulcers.

Altogether 26 lesions were induced in 13 patients, whereas none occurred in the controls $(p<0.001)$. Sutures caused most of the lesions (15), and those so induced had a mean maximum diameter of $2.3 \mathrm{~mm}$ and lasted for an average of four days. Ulcers induced mechanically were clinically indistinguishable from those usually seen in the patients, except that they were generally smaller and healed more quickly.

These findings confirm that mechanically induced injury of the oral mucosa may cause ulceration in people susceptible to aphthous stomatitis. Such a procedure may therefore be helpful in identifying subsets of patients.
\end{abstract}

\section{Introduction}

Recurrent aphthous stomatitis is the most common disease of oral mucous membranes. ${ }^{1}$ It is characterised by painful ulcers occurring singly or in crops. These ulcers typically last from seven to 14 days. Individual recurrences may be continuous or separated by varying periods of remission. The aetiology of the disease is not known but appears to be multifactorial.

This study was initiated to determine whether standardised mechanical injury would lead to ulcers in patients prone to aphthous stomatitis when compared with normal controls.

\section{Subjects and methods}

We studied 30 patients with recurrent aphthous stomatitis. Their ages ranged from 21 to 60 years (mean 36), and they had suffered from ulcerations for five to 55 years (mean 22.9 years). Nineteen

\footnotetext{
Laboratory of Oral Medicine, National Institute of Dental Research, National Institutes of Health, Bethesda, Maryland 20205

DAVID WRAY, MB, FDS, visiting associate

EDWARD A GRAYKOWSKI, MD, DDS, research scientist

ABNER LOUIS NOTKINS, MD, laboratory chief
}

were women (mean age 35.9 years) and 11 men (mean age 36.1 years) Twenty-eight patients clinically had recurrent aphthous stomatitis of the minor type, one had major aphthae, and one had herpetiform ulcers." Fifteen healthy volunteers without recurrent aphthous stomatitis and matched for age and sex served as controls.

The buccal mucosa was injured by three different methods. Firstly, local anaesthesia of the long buccal nerve was induced by injecting $0.5 \mathrm{ml} \mathrm{3 \%}$ mepivacaine without vasoconstrictor into the tissues overlying the junction of the ascending ramus and the body of the mandible. A further $0.5 \mathrm{ml}$ was injected submucosally into the buccal sulcus opposite the first mandibular molar. Each injection site served as a hypodermic needle wound. Secondly, once anaesthesia was established a $3 / 0$ black silk suture was inserted into the buccal mucosa below the linea alba, creating an entry and exit wound. This suture remained in situ for 24 hours before removal. Thirdly, a towe tenaculum was used to pierce the mucosa at a site $2 \mathrm{~cm}$ from the suture wound and removed immediately, leaving two sites of penetration of the oral mucosa. Each method therefore produced two puncture wounds. Only one side of the mouth was used, which was assigned at random. The procedure was carried out only when the area was free of spontaneous ulcers.

All patients and controls were seen on the first, third, fifth, and seventh days after the procedure, and lesions were measured and assessed. In addition, the subjects kept a daily record of the size, appearance, and degree of pain at the injured site. The size of the ulcers was recorded as maximum diameter $(\mathrm{mm})$. The patients scored the pain subjectively as 0 , painless; 1 , slight discomfort; 2 , moderate pain; and 3 , severe pain. If lesions persisted for more than seven days the patient was seen at three-day intervals until healing occurred.

\section{Results}

Of the 30 patients tested, 13 developed lesions at one or more of the puncture sites; none of the 15 controls developed ulcers (see table). This difference was significant $\left(\chi^{2}\right.$ test: $\left.p<0.001\right)$. Subject 1 developed ulcers at five of the six puncture sites: two at the site of the suture wound, two where the tenaculum had been placed, and one at the needle wound. Subjects 2 and 3 developed aphthous lesions at both the suture and tenaculum sites, and subject 4 developed lesions at both the suture and needle-puncture sites. Nine patients developed lesions in response to only one type of injury, but in four cases two lesions developed. In all, 13 patients developed 26 ulcers. Seventeen of the 30 patients failed to develop lesions, and in these and the controls the initial puncture wound did not progress, was associated with minimal erythema, and disappeared within 24 hours.

Sutures caused the most lesions. Thus 15 ulcers with a mean maximum diameter of $2.3 \mathrm{~mm}$ (range $1.0-3.0 \mathrm{~mm}$ ) were induced in this way. These ulcers lasted for an average of four days (range two to seven days) and were associated with a varying degree of pain (mean pain score 1.4 ; range $0-3$ ). Nine ulcers occurred at the tenaculum site with a mean diameter of $1.4 \mathrm{~mm}$ (range $1.0-5.0 \mathrm{~mm}$ ) and lasted 